\title{
Overexpression of long non-coding RNA zinc finger antisense 1 in acute myeloid leukemia cell lines influences cell growth and apoptosis
}

\author{
HAIFEI GUO ${ }^{1}$, LILI WU ${ }^{2}$, PU ZHAO ${ }^{1}$ and AIMEI FENG ${ }^{1}$ \\ Departments of ${ }^{1}$ Hematology and ${ }^{2}$ Medical Oncology, Third Affiliated Hospital of Wenzhou Medical University, \\ Ruian, Zhejiang 325200, P.R. China
}

Received March 31, 2016; Accepted March 6, 2017

DOI: $10.3892 / \mathrm{etm} .2017 .4535$

\begin{abstract}
The association between long non-coding RNA zinc finger antisense 1 (ZFAS1) and acute myeloid leukemia (AML) has not yet been investigated. The present study aimed to assess the potential role of ZFAS1 in AML cell proliferation and apoptosis. The expression of ZFAS1 mRNA in various AML cell lines (HL-60, KG-1, ML-1 and SKNO-1) was measured by reverse transcription-quantitative polymerase chain reaction. The results showed that ZFAS1 expression was increased in all four human AML cell lines compared with the control cell lines (T lymphocytic leukemia or Burkitt's lymphoma). Transfection with small interfering RNA into human AML cells established ZFAS1 knockdown. A cell-counting kit-8 (CCK-8) assay was used to investigate the effect of ZFAS1 on AML cell proliferation and the effect of ZFAS1 on the cell cycle and cell apoptosis was assessed using flow cytometry. Notably, the CCK-8 assay demonstrated that ZFAS1 knockdown inhibited cell proliferation in HL-60 and SKNO-1 cell lines and flow cytometry analysis indicated that ZFAS1 knockdown induced AML cell cycle G1 phase arrest and triggered cell apoptosis. Therefore, the present study indicated that ZFAS1 promoted the proliferation and inhibited the apoptosis of AML cells.
\end{abstract}

\section{Introduction}

Acute myeloid leukemia (AML) is a highly heterogeneous form of hematopoietic malignancies; aberrantly differentiated myeloid cells grow rapidly in the bone marrow and other tissues, thereby inhibiting normal hematopoiesis and immune function, and infiltrating other organs $(1,2)$. AML incidence increases with age and older patients typically exhibit a lower

Correspondence to: Dr Aimei Feng, Department of Hematology, Third Affiliated Hospital of Wenzhou Medical University, 108 Wansong Road, Ruian, Zhejiang 325200, P.R. China

E-mail: dr_fengaimei@sohu.com

Key words: long non-coding RNA, zinc finger antisense 1, proliferation, apoptosis, acute myeloid leukemia long-term overall survival rate (3). The formation of AML has been associated with multiple factors, including radiation, chemical degradation, viral infection and multiple susceptible genes (4). Although the overall prognosis of AML has improved markedly in recent years, the pathophysiological mechanism of AML development remains unknown. To increase the survival rate of patients with AML, it is of paramount importance to improve comprehension of its molecular pathogenesis and identify prognostic markers of AML.

Long non-coding RNAs (lncRNAs) are transcripts $>200$ nucleotides long that are not translated into proteins (5). Previous studies have indicated that various lncRNAs may be associated with specific biological processes, including chromatin modification, epigenetic regulation, the cell cycle, cell apoptosis and differentiation (6-8). LncRNAs are commonly dysregulated in the pathological processes of cancer, and may therefore serve as prognostic markers $(9,10)$.

It has been reported that zinc finger antisense 1 (ZFAS1), a newly identified lncRNA that maps to chromosome 20q13.13, is highly expressed in the mammary gland and downregulated in breast tumors (11). Li et al (12) and Thorenoor et al (13) reported that ZFAS1 functions as an oncogene in hepatocellular and colorectal carcinoma progression, and is associated with cancer cell cycle progression, metastasis and poor prognosis. Previous studies have also demonstrated that a variety of lncRNAs are closely associated with hematological malignancies (14-16). However, the role of ZFAS1 in AML remains unknown; therefore, the present study investigated its effects in various AML cell lines. Cell proliferation and apoptosis, which serve important roles in AML cell development and progression, were the primary mechanisms assessed to determine the effects of ZFAS1 on AML in the present study.

\section{Materials and methods}

Cell lines. Four human AML cell lines (HL-60, KG-1, ML-1 and SKNO-1), a T lymphocytic leukemia cell line (Jurkat) and a Burkitt's lymphoma cell line (Raji) were purchased from the Cell Bank of Chinese Academy of Sciences (Shanghai, China). The Jurkat and Raji cell lines were used as controls. The cells were all cultured in RPMI-1640 medium (Gibco; Thermo Fisher Scientific, Inc., Waltham, MA, USA) supplemented with 
$10 \%$ fetal bovine serum (Gibco; Thermo Fisher Scientific, Inc.) at $37^{\circ} \mathrm{C}$ in a humidified incubator in the presence of $5 \% \mathrm{CO}_{2}$. All cell lines were passaged for fewer than six months.

RNA extraction and reverse transcription-quantitative polymerase chain reaction ( $R T-q P C R)$. Total RNA was extracted from all cell lines using TRIzol ${ }^{\circledR}$ reagent (Invitrogen; Thermo Fisher Scientific, Inc.). $1 \mu \mathrm{g}$ Total RNA was reverse transcribed into cDNA using the PrimeScript ${ }^{\mathrm{TM}}$ RT Master Mix (Takara Biotechnology Co., Ltd., Dalian, China), according to the manufacturer's protocols. RT-qPCR was performed using the SYBR $^{\circledR}$ Premix DimerEraser ${ }^{\mathrm{TM}}$ (Takara Biotechnology Co., Ltd.) and an ABI Prism 7500 instrument (Applied Biosystems; Thermo Fisher Scientific, Inc.). The total PCR reaction volume was $20 \mu$, including SYBR Premix DimerEraser (2X) $10 \mu 1$, PCR forward primer $(10 \mu \mathrm{M}) 0.6 \mu \mathrm{l}$, PCR reverse primer $(10 \mu \mathrm{M}) 0.6 \mu \mathrm{l}$, ROX Reference Dye II (50X) $0.4 \mu$, template $2 \mu \mathrm{l}$ and sterile water $6.4 \mu \mathrm{l}$. The PCR cycling conditions were as follows: $95^{\circ} \mathrm{C}$ for $30 \mathrm{sec}$, followed by 40 cycles at $95^{\circ} \mathrm{C}$ for $5 \mathrm{sec}$ and $60^{\circ} \mathrm{C}$ for $34 \mathrm{sec}$, and a final extension step of $95^{\circ} \mathrm{C}$ for $15 \mathrm{sec}, 60^{\circ} \mathrm{C}$ for $1 \mathrm{~min}, 95^{\circ} \mathrm{C}$ for $15 \mathrm{sec}$ and $60^{\circ} \mathrm{C}$ for $15 \mathrm{sec}$. GAPDH was amplified as an internal control. The specific primer pairs were as follows: ZFAS1, forward, 5'-GCGAAA GCCATCTTTGGTTA-3' and reverse, 5'-GGGCAGGACAAT AGCGTATG-3'; and GAPDH, forward, 5'-GGACCTGAC CTGCCGTCTAG-3' and reverse, 5'-GTAGCCCAGGATGCC CTTGA-3'. Relative mRNA expression was determined using the $2^{-\Delta \Delta \mathrm{Cq}}$ method (17). All experiments were independently repeated at least three times.

Transient transfection of small interfering RNA (siRNA). The sequences of ZFAS1 siRNA were as follows: Forward, 5'-UCC AAAAUCCAUUCUGUACCC-3' and reverse, 5'-GUACAG AAUGGAUUUUGGAAG-3'. ZFAS1 siRNA and the negative control siRNA were purchased from Shanghai GenePharma Co., Ltd. (Shanghai, China). Transfection of siRNA into the AML cell lines HL-60 and SKNO-1 was performed with Lipofectamine ${ }^{\circledR} 2000$ (Invitrogen; Thermo Fisher Scientific, Inc.) according to the manufacturer's instructions. Following $48 \mathrm{~h}$ transfection, cells were collected and applied to the subsequent assay.

Cell proliferation assay. Following $24 \mathrm{~h}$ transfection with siRNA, $1 \times 10^{3}$ cells/well were seeded in 96-well plates with $100 \mu \mathrm{l}$ culture medium in triplicate. Cell proliferation was evaluated by water-soluble tetrazolium salt at the indicated time points using a Cell Counting kit-8 (CCK-8, Beyotime Institute of Biotechnology, Haimen, China). Briefly, $10 \mu$ l CCK-8 solution was added to each well and the mixture was incubated for $3 \mathrm{~h}$ at $37^{\circ} \mathrm{C}, 5 \% \mathrm{CO}_{2}$. Absorbance $(450 \mathrm{~nm})$ was detected at 24, 48, 72 and $96 \mathrm{~h}$ using a microplate reader (Epoch; BioTek Instruments, Inc., Winooski, VT, USA).

Flow cytometric analysis. For flow cytometric analysis, siRNA transfected HL-60 and SKNO-1 cells were collected following $48 \mathrm{~h}$ transfection. HL-60 and SKNO-1 cells were cultured in RPMI-1640 medium (Gibco; Thermo Fisher Scientific, Inc.) supplemented with $10 \%$ fetal bovine serum (Gibco; Thermo Fisher Scientific, Inc.). For cell cycle analysis, cells were fixed overnight in $70 \%$ cold ethanol, then resuspended in $20 \mathrm{mg} / \mathrm{ml}$ propidium iodide (PI; BD Biosciences, Franklin Lakes, NJ, USA). For apoptosis analysis, cells were stained with Annexin V-fluorescein isothiocyanate (FITC) and PI. Cells were then washed twice with ice-cold PBS and put into binding buffer (5 $\mu \mathrm{l}$ Annexin V-FITC and $5 \mu \mathrm{l} \mathrm{PI}$ ) for a $30 \mathrm{~min}$ incubation. A FACSCalibur ${ }^{\mathrm{TM}}$ flow cytometer (BD Biosciences) was used for analyzing the cell cycle or apoptosis. All experiments were independently repeated at least three times.

Statistical analysis. All data are expressed as mean \pm standard deviation. Differences between groups were analyzed using an independent-samples t-test. All P-values were two-sided and $\mathrm{P}<0.05$ was considered to indicate a statistically significant difference.

\section{Results}

Expression of ZFAS1 in AML cell lines. To determine whether ZFAS1 expression was dysregulated in AML cell lines, levels of ZFAS1 mRNA expression in HL-60, KG-1, ML-1, SKNO-1, Jurkat and Raji cell lines were measured using RT-qPCR. Relative levels of ZFAS1 mRNA were significantly increased in all human four AML cell lines compared with the T lymphocytic leukemia cell line or Burkitt's lymphoma cell line $(\mathrm{P}<0.001$ for HL-60, SKNO-1 and ML-1; P<0.01 for KG-1; Fig. 1A and B).

Efficiency of siRNA in downregulating ZFAS1 expression in AML cells. According to the aforementioned result, two AML cell lines (HL-60 and SKNO-1) were selected for ZFAS1 knockdown by transfection of siRNA, as expression of ZFAS1 was markedly increased in these cell lines compared with the KG-1 and ML-1 cell lines. RT-qPCR demonstrated that ZFAS1 was significantly decreased in HL-60 and SKNO-1 cells transfected with ZFAS1 siRNA compared with the respective negative control $(\mathrm{P}<0.001$; Fig. $1 \mathrm{C}$ and $\mathrm{D})$.

Downregulating ZFAS1 expression inhibits AML cell proliferation. The CCK-8 assay determined that the proliferation of HL-60 and SKNO-1 cells were both significantly inhibited following transfection with ZFAS1 siRNA after $72 \mathrm{~h}$ (both $\mathrm{P}<0.05$; Fig. 1E) and $96 \mathrm{~h}$ (both $\mathrm{P}<0.01$; Fig. 1F). Additionally, flow cytometric analysis of cell cycle distribution indicated that ZFAS1 knockdown significantly increased the percentage of G0/G1 phase HL-60 (from 47-64\%; P<0.01; Fig. 2A) and SKNO-1 cells (from 48-63\%; $\mathrm{P}<0.01$; Fig. 2B), and decreased the percentage of S-phase HL-60 (from 27-43\%; $\mathrm{P}<0.01$; Fig. 2A) and SKNO-1 cells (from 27-40\%; P<0.01; Fig. 2B). In summary, these results indicate that ZFAS1 promotes AML cell growth in vitro.

Downregulating ZFAS1 expression promotes AML cell apoptosis. To elucidate the function of ZFAS1 in the regulation of apoptosis in AML cells, flow cytometric analysis of HL-60 and SKNO-1 cell lines was performed. Compared with the respective negative control, ZFAS1 knockdown significantly increased the percentage of apoptotic AML HL-60 (5.5 $\pm 0.6 \%$ vs. $15.7 \pm 0.9 \%$; $\mathrm{P}<0.01$; Fig. $3 \mathrm{~A})$ and $\mathrm{SKNO}-1$ cells $(3.2 \pm 0.7 \%$ vs. $10.4 \pm 0.8 \%$; $\mathrm{P}<0.05$; Fig. $3 \mathrm{~B}$ ). These results suggest that ZFAS1 knockdown promotes AML cell apoptosis, which may contribute to the inhibition of AML progression. 
A

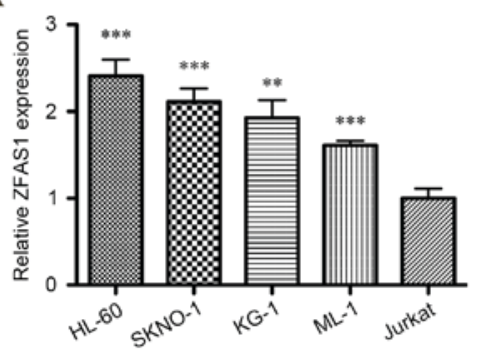

C

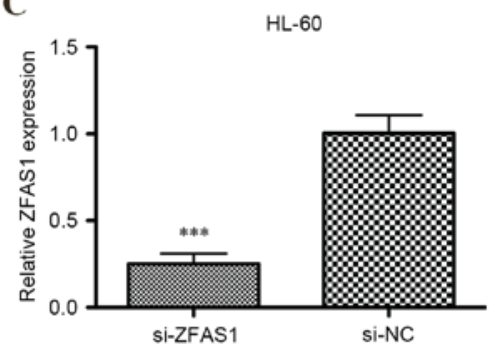

E

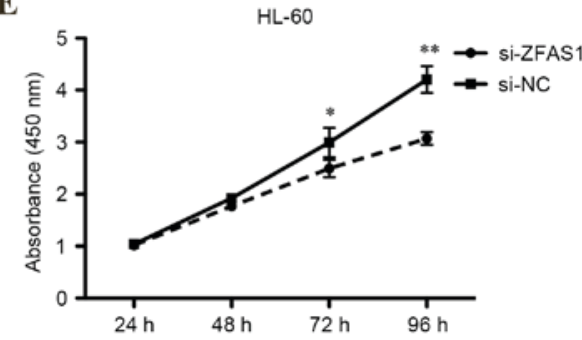

B

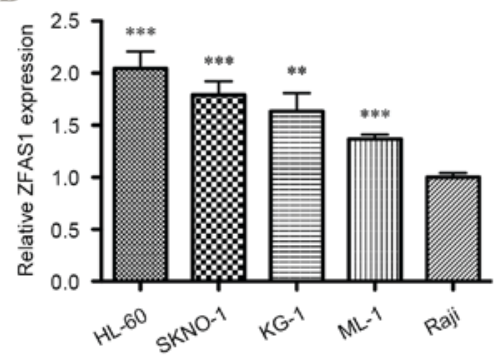

D

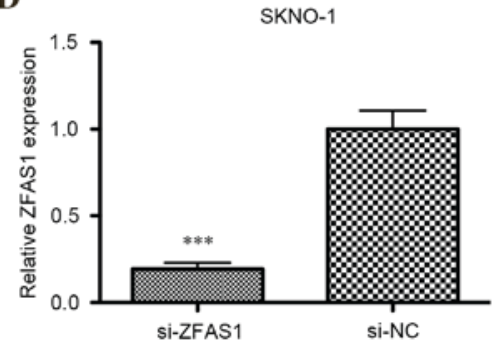

F

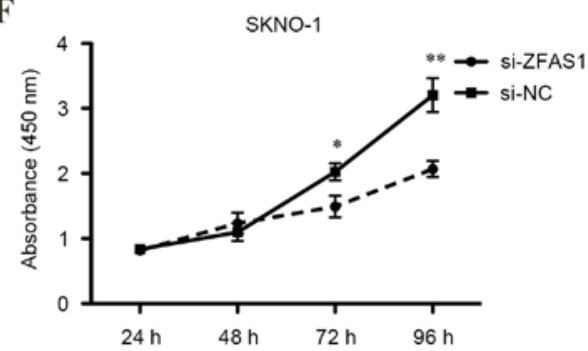

Figure 1. Reverse transcription-quantitative polymerase chain reaction was used to determine the relative mRNA expression of ZFAS1 in four acute myeloid leukemia cell lines (HL-60, SKNO-1, KG-1 and ML-1) compared with (A) T lymphocytic leukemia (Jurkat) and (B) Burkitt's lymphoma (Raji) cell lines. Knockdown effects of siRNA ZFAS1 in (C) HL-60 and (D) SKNO-1 cells. A cell counting kit-8 assay was used to investigate the function of long non-coding RNA ZFAS1. Downregulation of ZFAS1 inhibited (E) HL-60 and (F) SKNO-1 cell growth. Statistics were performed using the independent samples t-test. Data are presented as the mean \pm standard deviation. All assays were performed in triplicate. ${ }^{*} \mathrm{P}<0.05,{ }^{* * *} \mathrm{P}<0.01$ and ${ }^{* * *} \mathrm{P}<0.001$ vs. control. si, small interfering; NC, negative control; ZFAS1, zinc finger antisense 1.
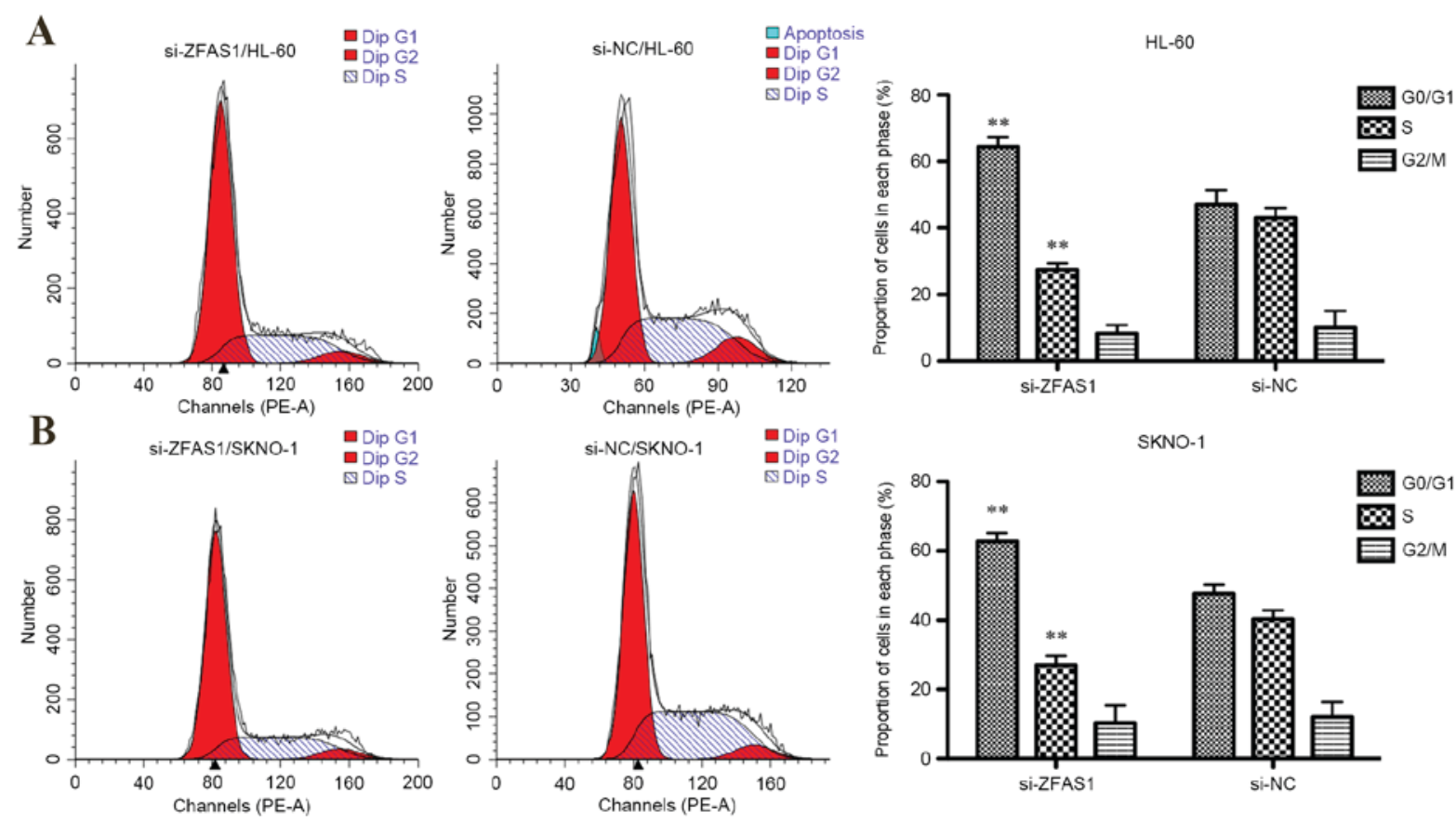

Figure 2. Flow cytometric analysis was used to determine the role of ZFAS1 on the cell cycle in HL-60 and SKNO-1 cells. Downregulation of ZFAS1 promoted (A) HL-60 and (B) SKNO-1 cell cycle arrest at the G0/G1 phase. Statistical analysis was performed using the independent samples t-test. Data are presented

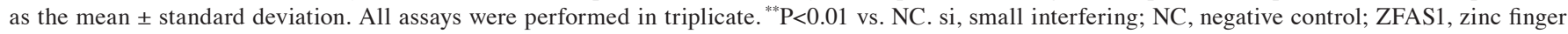
antisense 1 . 
A

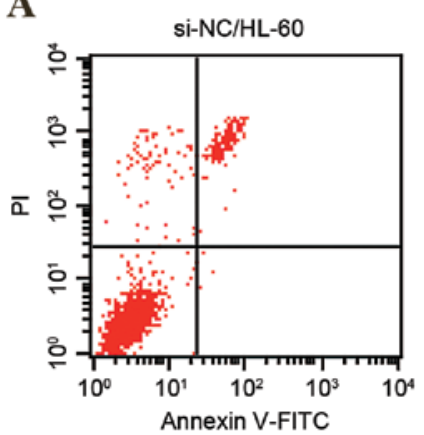

B

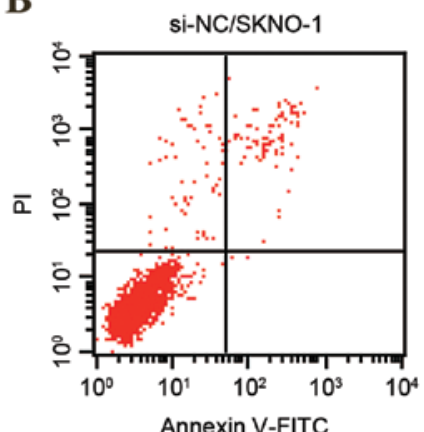

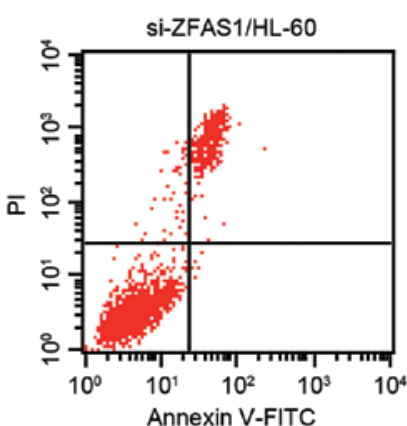
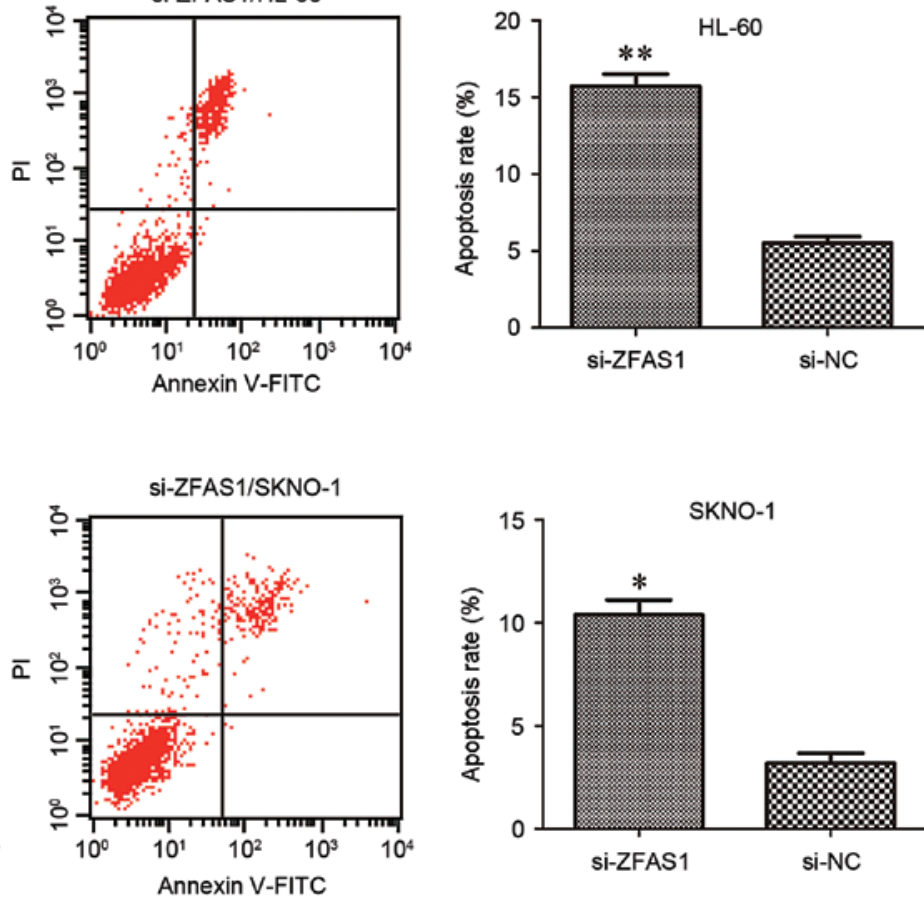

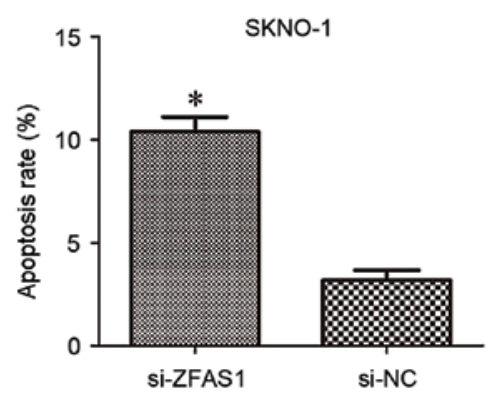

Figure 3. Flow cytometric analysis was used to determine the role of ZFAS1 in HL-60 and SKNO-1 cell apoptosis. Downregulation of ZFAS1 stimulated (A) HL-60 and (B) SKNO-1 cell apoptosis. Statistical analysis was performed using the independent samples t-test. Data are presented as the mean \pm standard deviation. All assays were performed in triplicate. ${ }^{*} \mathrm{P}<0.05,{ }^{* *} \mathrm{P}<0.01$ vs. NC. si, small interfering; NC, negative control; ZFAS1, zinc finger antisense 1 ; FITC, fluorescein isothiocyanate; PI, propidium iodide.

\section{Discussion}

LncRNAs are a newly identified type of non-coding RNA that have been reported to be dysregulated in a number of different diseases, including carcinoma $(18,19)$. The importance of lncRNAs in the development of cancer may be associated with their ability to influence cellular function through different mechanisms, such as proliferation, apoptosis and differentiation (20-22). In present study, CCK-8 assay and cell cycle distribution analysis demonstrated that ZFAS1 was able to induce AML cell proliferation. Furthermore, the apoptosis assay indicated that ZFAS1 inhibited apoptosis in AML cells. These results suggest that ZFAS1 knockdown suppresses AML HL-60 and SKNO-1 cell proliferation and survival, and that ZFAS1 may act as an oncogenic lncRNA.

It has previously been determined that ZFAS1 is downregulated in breast cancer and that it acts as a putative tumor suppressor (11). Previous studies have reported that ZFAS1 is overexpressed in hepatocellular and colorectal cancer tissues and cell lines $(12,13)$. In the current study, it was demonstrated that ZFAS1 has an oncogenic role in AML cell lines. However, the underlying mechanism of ZFAS1 in the progression of AML remains unclear.

In recent years, a number of articles have reported that IncRNAs have the ability to target and regulate microRNAs (miRs) $(23,24)$. It is widely acknowledged that miRNAs regulate the expression of multiple target genes that encode proteins, which may lead to biological alterations in function $(25,26)$. Li et al (12) identified that ZFAS1 functions as an oncogene in hepatocellular carcinoma progression by binding miR-150 and abrogating its tumor-suppressive function. Furthermore,
Li et al (12) indicated that miR-150 was able to repress hepatocellular carcinoma cell invasion by inhibiting ZEB1 and the matrix metalloproteinases (MMPs), MMP14 and MMP16. It was also demonstrated that other IncRNAs are associated with cell growth and apoptosis regulation by regulating multiple target genes, including phosphoinositide-3-kinase, Akt and extracellular signal-regulated kinases $(27,28)$. Although it has been demonstrated that IncRNAs influence epigenetic gene regulation (6,7), proliferation (7), apoptosis $(6,7)$ and prognosis (8) in solid tumors, few studies have identified their effects on AML. Garzon et al (29) assessed whether a lncRNA expression profile was associated with clinical features, molecular abnormalities and outcome in older patients with cytogenetically normal AML and revealed that patients with an unfavorable lncRNA score had a shorter overall survival and disease-free survival rate than those with a favorable lncRNA score. These results are consistent with those from the present study.

In conclusion, the present study demonstrated that lncRNA ZFAS1 promoted the proliferation and suppressed the apoptotic rate of AML cells. Additionally, the results of the present study indicated that ZFAS1 may act as an oncogenic lncRNA.

\section{Acknowledgements}

The present study was supported by funding from the Departments of Hematology and Medical Oncology, Third Affiliated Hospital of Wenzhou Medical University, Ruian, China). The funding sources had no role in the study design, in the collection, analysis and interpretation of data, writing of the manuscript or in the decision to submit the manuscript for publication. 


\section{References}

1. Sanz GF, Sanz MA, Vallespí T, Cañizo MC, Torrabadella M, García S, Irriguible D and San Miguel JF: Two regression models and a scoring system for predicting survival and planning treatment in myelodysplastic syndromes: A multivariate analysis of prognostic factors in 370 patients. Blood 74: 395-408, 1989.

2. Leith CP, Kopecky KJ, Godwin J, McConnell T, Slovak ML, Chen IM, Head DR, Appelbaum FR and Willman CL: Acute myeloid leukemia in the elderly: Assessment of multidrug resistance (MDR1) and cytogenetics distinguishes biologic subgroups with remarkably distinct responses to standard chemotherapy. A Southwest Oncology Group study. Blood 89: 3323-3329, 1997.

3. Appelbaum FR, Baer MR, Carabasi MH, Coutre SE, Erba HP, Estey E, Glenn MJ, Kraut EH, Maslak P, Millenson M, et al: NCCN practice guidelines for acute myelogenous leukemia. Oncology (Williston Park) 14: 53-61, 2000.

4. Hope KJ, Jin L and Dick JE: Human acute myeloid leukemia stem cells. Arch Med Res 34: 507-514, 2003.

5. Ding J, Lu B, Wang J, Wang J, Shi Y, Lian Y, Zhu Y, Wang J, Fan Y, Wang Z, et al: Long non-coding RNA Loc554202 induces apoptosis in colorectal cancer cells via the caspase cleavage cascades. J Exp Clin Cancer Res 34: 100, 2015.

6. Mercer TR, Dinger ME and Mattick JS: Long non-coding RNAs: Insights into functions. Nat Rev Genet 10: 155-159, 2009.

7. Fachel AA, Tahira AC, Vilella-Arias SA, Maracaja-Coutinho V, Gimba ER, Vignal GM, Campos FS, Reis EM and Verjovski-Almeida S: Expression analysis and in silico characterization of intronic long noncoding RNAs in renal cell carcinoma: Emerging functional associations. Mol Cancer 12: 140, 2013.

8. Kim K, Jutooru I, Chadalapaka G, Johnson G, Frank J, Burghardt R, Kim S and Safe S: HOTAIR is a negative prognostic factor and exhibits pro-oncogenic activity in pancreatic cancer. Oncogene 32: 1616-1625, 2013.

9. Ellinger J, Alam J, Rothenburg J, Deng M, Schmidt D, Syring I, Miersch H, Perner S and Müller SC: The long non-coding RNA lnc-ZNF180-2 is a prognostic biomarker in patients with clear cell renal cell carcinoma. Am J Cancer Res 5: 2799-2807, 2015.

10. Chen X, Liu L and Zhu W: Up-regulation of long non-coding RNA CCAT2 correlates with tumor metastasis and poor prognosis in cervical squamous cell cancer patients. Int J Clin Exp Pathol 8: 13261-13266, 2015.

11. Askarian-Amiri ME, Crawford J, French JD, Smart CE, Smith MA, Clark MB, Ru K, Mercer TR, Thompson ER, Lakhani SR, et al: SNORD-host RNA Zfas1 is a regulator of mammary development and a potential marker for breast cancer. RNA 17: 878-891, 2011.

12. Li T, Xie J, Shen C, Cheng D, Shi Y, Wu Z, Deng X, Chen H, Shen B, Peng C, et al: Amplification of long noncoding RNA ZFAS1 promotes metastasis in hepatocellular carcinoma. Cancer Res 75: 3181-3191, 2015.

13. Thorenoor N, Faltejskova-Vychytilova P, Hombach S, Mlcochova J, Kretz M, Svoboda M and Slaby O: Long non-coding RNA ZFAS1 interacts with CDK1 and is involved in p53-dependent cell cycle control and apoptosis in colorectal cancer. Oncotarget 7: 622-637, 2016.

14. Xing CY, Hu XQ, Xie FY, Yu ZJ, Li HY, Bin-Zhou, Wu JB, Tang LY and Gao SM: Long non-coding RNA HOTAIR modulates c-KIT expression through sponging miR-193a in acute myeloid leukemia. FEBS Lett 589: 1981-1987, 2015.
15. Hirano T, Yoshikawa R, Harada H, Harada Y, Ishida A and Yamazaki T: Long noncoding RNA, CCDC26, controls myeloid leukemia cell growth through regulation of KIT expression. Mol Cancer 14: 90, 2015

16. Alvarez-Dominguez JR, Hu W, Gromatzky AA and Lodish HF: Long noncoding RNAs during normal and malignant hematopoiesis. Int J Hematol 99: 531-541, 2014.

17. Livak KJ and Schmittgen TD: Analysis of relative gene expression data using real-time quantitative PCR and the 2(-Delta Delta C(T)) Method. Methods 25: 402-408, 2001.

18. Yang F, Huo XS, Yuan SX, Zhang L, Zhou WP, Wang F and Sun SH: Repression of the long noncoding RNA-LET by histone deacetylase 3 contributes to hypoxia-mediated metastasis. Mol Cell 49: 1083-1096, 2013

19. Gupta RA, Shah N, Wang KC, Kim J, Horlings HM, Wong DJ, Tsai MC, Hung T, Argani P, Rinn JL, et al: Long non-coding RNA HOTAIR reprograms chromatin state to promote cancer metastasis. Nature 464: 1071-1076, 2010.

20. Ma MZ, Li CX, Zhang Y, Weng MZ, Zhang MD, Qin YY, Gong W and Quan ZW: Long non-coding RNA HOTAIR, a c-Myc activated driver of malignancy, negatively regulates miRNA-130a in gallbladder cancer. Mol Cancer 13: 156, 2014.

21. Wu XS, Wang XA, Wu WG, Hu YP, Li ML, Ding Q, Weng H, Shu YJ, Liu TY, Jiang L, et al: MALAT1 promotes the proliferation and metastasis of gallbladder cancer cells by activating the ERK/MAPK pathway. Cancer Biol Ther 15: 806-814, 2014.

22. Chen CL, Tseng YW, Wu JC, Chen GY, Lin KC, Hwang SM and $\mathrm{Hu}$ YC: Suppression of hepatocellular carcinoma by baculovirus-mediated expression of long non-coding RNA PTENP1 and MicroRNA regulation. Biomaterials 44: 71-81, 2015.

23. Nie W, Ge HJ, Yang XQ, Sun X, Huang H, Tao X, Chen WS and Li B: LncRNA-UCA1 exerts oncogenic functions in non-small cell lung cancer by targeting miR-193a-3p. Cancer Lett 371: 99-106, 2016

24. Kang Y, Song J, Kim D, Ahn C, Park S, Chun CH and Jin EJ: PCGEM1 stimulates proliferation of osteoarthritic synoviocytes by acting as a sponge for miR-770. J Orthop Res 34: 412-418, 2016.

25. Han F, Wu Y and Jiang W: MicroRNA-18a decreases choroidal endothelial cell proliferation and migration by inhibiting HIF1A expression. Med Sci Monit 21: 1642-1647, 2015.

26. Yan G, Li B, Xin X, Xu M, Ji G and Yu H: MicroRNA-34a promotes hepatic stellate cell activation via targeting ACSL1. Med Sci Monit 21: 3008-3015, 2015.

27. Redis RS, Sieuwerts AM, Look MP, Tudoran O, Ivan C, Spizzo R, Zhang X, de Weerd V, Shimizu M, Ling H, et al: CCAT2, a novel long non-coding RNA in breast cancer: Expression study and clinical correlations. Oncotarget 4: 1748-1762, 2013.

28. Cai Y, He J and Zhang D: Long noncoding RNA CCAT2 promotes breast tumor growth by regulating the Wnt signaling pathway. Onco Targets Ther 8: 2657-2664, 2015.

29. Garzon R, Volinia S, Papaioannou D, Nicolet D, Kohlschmidt J, Yan PS, Mrózek K, Bucci D, Carroll AJ, Baer MR, et al: Expression and prognostic impact of lncRNAs in acute myeloid leukemia. Proc Natl Acad Sci U S A 111: 18679-18684, 2014. 